\title{
Prevalence of diabetes mellitus and its relation with obesity in Turaif (Saudi Arabia) in 2017
}

Reem Sebeh Alhazmi ${ }^{1}$, Amer Ahmed Balla Ahmed ${ }^{2}$, Maha Hazzaa Alshalan ${ }^{1}$, Zuhur Dhaher Alfuhigi ${ }^{1}$, Shoroq Faisal Alhazmi ${ }^{1}$, Amjad Naif Aldughmi ${ }^{1}$, Nada Naif Alshammari ${ }^{1}$, Anwar Eid Alruwaili ${ }^{1}$, Ghadah Saleem Alenezi ${ }^{1}$, Taif Shayish Alanazi ${ }^{1}$, Shouq Amjad Almadani ${ }^{1}$

${ }^{1}$ Student, Faculty of Medicine, Northern Border University, Arar, Saudi Arabia

${ }^{2}$ Assistant Professor, Department of Internal Medicine, Northern Border University, Arar, Saudi Arabia

\section{Type of article: Original}

\begin{abstract}
Background: The significant increase in the prevalence of obesity over past decades caused the concomitant rise in the incidence of glucose intolerance and diabetes.

Objective: To determine the prevalence of diabetes among Saudi nationals in Turaif, Kingdom of Saudi Arabia and to examine the association between diabetes and obesity in the studied population.

Methods: This study was conducted during the period from May 01 to May 31, 2017. Data was collected from 402 individuals aged between 6-63 years via a predesigned questionnaire covering medical history of diabetes, age and sex. Body weight and height was measured to calculate BMI. Data were analyzed by SPSS version 15, using descriptive statistics and Chi-Square test.

Results: Mean age $( \pm$ SD) was $23.27( \pm 13.509)$ years, male to female ratio was $38.1 \%$ to $61.9 \%$. The total prevalence of DM among the studied population was $4.5 \%$, pre-diabetic cases were $7.5 \%$. There is significant effect of age, sex and BMI on the occurrence of diabetes among the studied population $(\mathrm{p}<0.05)$.

Conclusions: Awareness campaigns and prevention programs about diabetes should be instituted and control strategies should be implemented. There is a need for a diabetes screening and management programs, focusing on access to health care in the city.

Keywords: Diabetes mellitus; Prevalence; Obesity; Turaif, Saudi Arabia; Body Mass Index
\end{abstract}

\section{Introduction}

Diabetes mellitus (DM) is a major public health problem worldwide. There is a rapidly increasing number of patients with diabetes mellitus (DM) worldwide; in fact, this disease is being described as an 'epidemic' $(1,2)$. In 2007, 240 million people in the world suffered from DM (3). An increase in body fat is generally associated with increased risk of metabolic diseases such as type 2 diabetes mellitus, hypertension and dyslipidemia (4). However, not all overweight or obese patients have metabolic diseases, and vice versa. Defining the relationship between body weight and metabolic diseases is critical toward a better understanding of the underlying pathophysiological processes leading to these diseases (5). Health information regarding such relationships is often obtained through the use of surveys. Population surveys are a well-recognized, and a much utilized method to assess the prevalence of diseases as well as obtain other health-related information $(6,7)$. Several studies have reported a strong association between excess weight and increased risk of death, placing the overweight group at a $40 \%$ higher and the obese group at up to $300 \%$ higher risk of death than individuals whose BMI is normal $\left(18.5 \leq \mathrm{BMI}<25 \mathrm{~kg} / \mathrm{m}^{2}\right)(8-10)$. In this study, we estimate the lifetime risk of diabetes (risk from age 18 years until $>65$ ) by baseline age, sex, and BMI for Turaif, Kingdom of Saudi Arabia population, and present the results in a form suitable for communication with individuals at risk and with policy makers. A study conducted in the U.S showed that among DM-diagnosed individuals; elevated BMIs were associated with progressively higher risk of adverse outcomes. For women, hazard ratio (HR) of insulin dependence ranged from a 1.77 at $25 \leq \mathrm{BMI} \leq 27.49 \mathrm{~kg} / \mathrm{m}^{2}$ to 3.57 at $\mathrm{BMI} \geq 40 \mathrm{~kg} / \mathrm{m}^{2}$. Another

\section{Corresponding author:}

Reem Sebeh Alhazmi, Faculty of Medicine, Northern Border University, Arar, Saudi Arabia.

Tel: +966.556479146, Email: dr.reemsal@gmail.com

Received: July 12, 2017, Accepted: August 14, 2017, Published: October 2017

iThenticate screening: August 12, 2017, English editing: September 12, 2017, Quality control: September 15, 2017

(C) 2017 The Authors. This is an open access article under the terms of the Creative Commons Attribution-NonCommercialNoDerivs License, which permits use and distribution in any medium, provided the original work is properly cited, the use is non-commercial and no modifications or adaptations are made. 
study in Saudi Arabia (11) conducted to show the relation between age and sex with DM, showed that four thousand and four subjects $(23.7 \%)$, out of 1,6917 were diagnosed to have DM. Thus, the overall prevalence of DM obtained from this study is $23.7 \%$ in the Kingdom of Saudi Arabia. The prevalence in males and females were $26.2 \%$ and $21.5 \%(p<0.00001)$. The calculated age-adjusted prevalence for the Saudi population for the year 2000 is $21.9 \%$. Another study in the U.S (12) which included 12,179 cases (mean age: 55, 43\% male) and 25,177 controls (mean age: $56,45 \%$ male) found a positive association between BMI and the risk of DM diagnosis. The strength of this association increased with BMI category (RR [95\% confidence interval]: overweight, 1.5 [1.4-1.6]; Obesity Class I, 2.5 [2.3-2.6]; Obesity Class II, 3.6 [3.4-3.8]; Obesity Class III, 5.1 [4.7-5.5]). Additionally, in Saudi Arabia, a further study (13) revealed that diabetes' prevalence was $34.1 \%$ in males and $27.6 \%$ in females $(p<0.0001)$. The study showed the mean (SD) age for onset of diabetes in males and females to be 57.5 (13.1) and 53.4 (13.1) years, respectively $(\mathrm{p}<0.0001)$. There was higher prevalence in Females $<50$ years old than in males of equivalent age range $34.1 \%$ and $25.1 \%$, respectively $(\mathrm{p}<0.0001)$. There was a decreased prevalence of diabetes in patients older than 70 years. BMI prevalence of $\geq 25$ was $72.5 \%$, and among diabetic patients, the prevalence of body mass index of $\geq 25$ was $85.7 \%(p<0.0001)$. Higher prevalence of obesity (BMI $\geq 25)$ was seen in females $(87.7 \%)$ as compared to males $(83.1 \%)(p=0.008)$. The aim of our study was to determine the prevalence of diabetes among Saudi Nationals in Turaif, Saudi Arabia and to examine the association between diabetes and obesity in the studied population.

\section{Material and Methods}

This cross-sectional study carried out on 402 Saudi nationals in Turaif, Kingdom of Saudi Arabia during the period from May 01 to May 31, 2017. The study sample consisted of both sexes aged between 6-63 years. The sample size was calculated using the sample size equation: $n=z^{2} p(1-p) / e^{2}$. Systematic random sampling technique was followed in sampling procedure. Participants were interviewed with structured questionnaires covering the following items:

1) Socio-demographic characteristics including age and sex.

2) Anthropometric examination included height and weight measurements with the use of a calibrated balance beam scale and a wall-mounted stadiometer and calculation of body mass index (BMI). Normal weight was defined as $\mathrm{BMI}<25 \mathrm{~kg} / \mathrm{m}^{2}$, overweight as $25 \leq \mathrm{BMI} \leq 30 \mathrm{~kg} / \mathrm{m}^{2}$ and obesity as $\mathrm{BMI} \geq 30 \mathrm{~kg} / \mathrm{m}^{2}$.

3) Blood sample is drawn under complete septic conditions to determine random blood glucose level. Person considered diabetic if random blood sugar was $\geq 200 \mathrm{ml} / \mathrm{dl}$.

Permission to conduct the study was obtained from the Research and Ethics Committee at the College of Medicine, Northern Border University, Saudi Arabia. The questionnaire included a brief introduction to the participants by explaining the aims and significance of the study. Confidentiality of data was maintained throughout the study. Collected data were coded and analyzed by SPSS version 15 (SPSS Inc., Chicago, Illinois, USA). The Chi-square test was used as a test of significance, and differences were considered significant at p-value 0.05 or less.

\section{Results}

Table 1 illustrates the Socio-demographic characteristics of studied cases, in Turaif city, northern Saudi Arabia, 2017. The table showed that mean age $( \pm$ SD) was $23.27( \pm 13.509)$, male to female ratio was $38.1 \%$ to $61.9 \%$. Table 2 illustrates prevalence of DM among studied cases in Turaif city, northern Saudi Arabia, 2017. The total prevalence of DM among studied cases was $4.5 \%$, pre-diabetic cases were $7.5 \%$ and normal cases were $88.1 \%$. According to our findings, 18 people (4.5\%) were diabetic cases, 30 people (7.5\%) were pre-diabetic cases and 345 people $(88.1 \%)$ were normal cases. Table 3 Illustrates the relationship between diabetes, age, Sex, and BMI among studied cases in Turaif city, northern Saudi Arabia, 2017. According to Table 3, there are significant effects of age and BMI $(p<0.05)$; but there is no significant effect of $\operatorname{sex}(p>0.05)$.

Table 1. Socio-demographic characteristics of studied cases, in Turaif city, northern Saudi Arabia, 2017

\begin{tabular}{|l|l|l|l|}
\hline \multicolumn{2}{|l|}{ Parameter } & Frequency $(\mathrm{n}=402)$ & $\%$ \\
\hline Age (year) & $0-16$ & 139 & 34.6 \\
\cline { 2 - 4 } & $17-35$ & 188 & 46.8 \\
\cline { 2 - 4 } & $36-65$ & 75 & 18.7 \\
\hline \multirow{2}{*}{ Sex } & Male & 153 & 38.1 \\
\cline { 2 - 4 } & Female & 249 & 61.9 \\
\hline
\end{tabular}


Table 2. Prevalence of DM among studied cases in Turaif city, northern Saudi Arabia, 2017

\begin{tabular}{|l|l|l|}
\hline Diagnosis & Frequency $(\mathrm{n}=402)$ & $\%$ \\
\hline Normal & 354 & 88.1 \\
\hline Pre-diabetic & 30 & 7.5 \\
\hline Diabetic & 18 & 4.5 \\
\hline Total & 402 & 100.0 \\
\hline
\end{tabular}

Table 3. Relationship between diabetes, age, Sex, and BMI among studied cases in Turaif city, northern Saudi Arabia, 2017

\begin{tabular}{|c|c|c|c|c|c|c|c|}
\hline \multicolumn{2}{|c|}{ Variables } & \multicolumn{3}{|c|}{ Diagnosis; n (\%) } & \multirow{2}{*}{$\begin{array}{l}\text { Total }(\mathrm{n}=402) ; \\
\mathrm{n}(\%)\end{array}$} & \multirow{4}{*}{$\begin{array}{l}\begin{array}{l}\text { Chi- } \\
\text { Square }\end{array} \\
34.346\end{array}$} & \multirow{2}{*}{$\begin{array}{l}\begin{array}{l}\mathrm{p}- \\
\text { value }\end{array} \\
0.00\end{array}$} \\
\hline \multirow{3}{*}{$\begin{array}{l}\text { Age } \\
\text { (year) }\end{array}$} & $0-16$ & \begin{tabular}{|l}
$\begin{array}{l}\text { Normal } \\
(\mathrm{n}=354)\end{array}$ \\
$129(36.4)$
\end{tabular} & $\begin{array}{l}\text { Pre-diabetic } \\
(\mathrm{n}=30)\end{array}$ & \begin{tabular}{|l|}
$\begin{array}{l}\text { Diabetic } \\
(\mathrm{n}=18)\end{array}$ \\
$2(11.1)$
\end{tabular} & & & \\
\hline & $17-35$ & $173(48.9)$ & $10(33.3)$ & $5(27.8)$ & $188(46.8)$ & & \\
\hline & $36-65$ & $52(14.7)$ & $12(40.0)$ & $11(61.1)$ & $75(18.7)$ & & \\
\hline \multirow{5}{*}{$\begin{array}{l}\text { BMI } \\
\left(\mathrm{kg} / \mathrm{m}^{2}\right)\end{array}$} & Underweight & $107(30.2)$ & $5(16.7)$ & $1(5.6)$ & $113(28.1)$ & \multirow[t]{5}{*}{17.295} & \multirow[t]{5}{*}{0.027} \\
\hline & $\begin{array}{l}\text { Healthy } \\
\text { weight }\end{array}$ & $94(26.6)$ & $8(26.7)$ & $4(22.2)$ & $106(26.4)$ & & \\
\hline & Overweight & $84(23.7)$ & $6(20.0)$ & $4(22.2)$ & $94(23.4)$ & & \\
\hline & Obese & $58(16.4)$ & $8(26.7)$ & $7(38.9)$ & $73(18.2)$ & & \\
\hline & $\begin{array}{l}\text { Morbid } \\
\text { obesity }\end{array}$ & $11(3.1)$ & $3(10.0)$ & $2(11.1)$ & $16(4.0)$ & & \\
\hline \multirow[t]{2}{*}{ Sex } & Male & $140(39.5)$ & $9(30.0)$ & $4(22.2)$ & $153(38.1)$ & & \\
\hline & Female & $214(60.5)$ & $21(70.0)$ & $14(77.8)$ & $249(61.9)$ & & \\
\hline
\end{tabular}

\section{Discussion}

Diabetes mellitus (DM) is a major public health problem worldwide, and it is a known risk factor for a lot of diseases. Four major modifiable risk factors for diabetes have been identified in previous studies: age, sex and body mass index BMI. This study was conducted in Turaif, Kingdom of Saudi Arabia among 402 females and males aged between (0-65). The aim of the study was to determine the prevalence of diabetes among the Saudi population in Turaif, Kingdom of Saudi Arabia, to make comparisons to the prevalence in the long-term population and examine the association of prevalence with sex, age and BMI. The study shows the prevalence of DM was $4.5 \%$, pre-diabetic people $7.5 \%$ and normal people $88.1 \%$. An Al-Nozha et al. study found that 4,004 subjects $(23.7 \%)$ out of 16,917 were diagnosed to have DM (11). Another study in the Kingdom of Saudi Arabia found that diabetes mellitus was present in $30 \%$ of the studied sample (13). In our study, although the prevalence of DM was higher in females than in males, the difference was not significant. Data from other studies agreed with our findings (14-16). Some studies found a relationship between DM and gender (17-19). The Al-Nozha et al. study (11) did not agree with these results as it shows diabetic male subjects overall as having higher prevalence of $26.2 \%$ compared to female subjects of $21.5 \%$ and this was statistically significant $(\mathrm{p}<0.0001)$. A study conducted in Canada (20) found a higher proportion of males (54\% males, $46 \%$ females) among Canadian patients with diabetes. Studies in the United States found a higher proportion of females ( $42 \%$ males, $58 \%$ females) with diabetes (21). Age is known to be an important determinant of diabetes since blood glucose concentrations tend to rise with age (19). Prevalence of diabetes increased with age, from $11.1 \%$ in the 0 to 16 year age group to about $27.8 \%$ in the 17 to 35 age group up to $61.1 \%$ in the age group 36 to 65 . Results of the Canadian study agreed with our result, as it showed prevalence of diabetes increased with age, from $0.5 \%$ in the 12 - to 34 -year age group to about 10 to $14 \%$ in the 75 and older age group (20). Another study among an Iranian urban population (14) showed that the prevalence of DM increased with advancing age from $4 \%$ in subjects $30-39$ to $22.9 \%$ in subjects $\geq 60(\mathrm{p}<0.001)$. Other studies have also indicated that the prevalence of DM increases with age $(15,22)$. Regarding BMI, higher-than-normal BMI was consistently associated with an increased probability of being diagnosed as diabetic. And since obesity affects glucose metabolism, so increases the risk of diabetes mellitus. Therefore, it is recommended that both men and women should avoid becoming overweight. We found that the prevalence of diabetes increased with obesity -BMI in both males and females, as only $5.6 \%$ of diabetics were underweight, $22.2 \%$ were healthy weight, $22.2 \%$ were overweight and $38.9 \%$ were obese. This is consistent with the other published results. Those studies, including case control studies (23-26) and cross-sectional studies $(27-31)$ report a significant $\mathrm{p}<0.05)$ positive association between obesity and diabetes. One cohort study in 1990 (32) failed to show a significant association ( $\mathrm{p}=0.44)$, probably due 
to its small number of diabetic patients identified in the follow-up period. A biological basis has also been proposed for the effect of obesity on diabetes: Obesity is partly genetically determined $(33,34)$ and partly an indicator of sugar imbalance, reflecting the difference between energy intake and energy expenditure (35-37). Another study (20) showed that diabetes prevalence was higher for those males with BMI greater than 27(4.4\%) compared to males with acceptable BMI of 20 to 25 (1.6\%) and for those females with BMI greater than 27 (4.8\%) compared to females with acceptable BMI (0.9\%). Another study showed that among DM diagnosed individuals, elevated BMIs were associated with progressively higher risk of adverse outcomes. For women, hazard ratio (HR) of insulin dependence ranged from a 1.77 at $25 \leq \mathrm{BMI} \leq 27.49 \mathrm{~kg} / \mathrm{m}^{2}$ to 3.57 at $\mathrm{BMI} \geq 40 \mathrm{~kg} / \mathrm{m}^{2}(10)$.

\section{Conclusions}

The total prevalence rate of DM among the studied population of Turaif city, northern Saudi Arabia was 4.5\%. Prediabetic cases were 7.5\% which suggest a need for a diabetes screening and management programs, focusing on access to health care in the city. Community level awareness programs have to be organized. Healthcare providers must be aware of community perceptions and practices toward diabetes.

\section{Acknowledgments:}

The authors are very grateful to Northern Border University for their continuous support and guidance. The authors would also like to extend their appreciation to, Mahmoud Mohammed Alsharif and Nour Homoud Alanazi for helping us in collection of data.

\section{Conflict of Interest:}

There is no conflict of interest to be declared.

\section{Authors' contributions:}

All authors contributed to this project and article equally. All authors read and approved the final manuscript.

\section{References:}

1) Guariguata L, Whiting D, Weil C, Unwin N. The International Diabetes Federation diabetes atlas methodology for estimating global and national prevalence of diabetes in adults. Diabetes Res Clin Pract 94: 2011; 322-32. doi: 10.1016/j.diabres.2011.10.040

2) Yoon KH, Lee JH, Kim JW, Cho JH, Choi YH, et al. Epidemic obesity and type 2 diabetes in Asia. Lancet. 2006; 368(9548):1681-88. DOI: 10.1016/S0140-6736(06)69703-1

3) Albache N, Al Ali R, Rastam S, Fouad FM, Mzayek F, Maziak W. Epidemiology of Type 2 diabetes mellitus in Aleppo, Syria. J Diabetes. 2010 Jun;2(2):85-91. DOI: 10.1111/j.1753-0407.2009.00063.X

4) World Health Organization. Obesity and Overweight Facts. Available from: who.int/hpr/NPH/docs/gs_obesity.pdf

5) H E Bays, R H Chapman, and S Grandy, the SHIELD Investigators'. The relationship of body mass index to diabetes mellitus, hypertension and dyslipidaemia: comparison of data from two national surveys. Int $\mathrm{J}$ Clin Pract. 2007;61(5): 737-47. DOI: 10.1111/j.1742-1241.2007.01336.x

6) Hirschfeld RM, et al. Screening for bipolar disorder in the community. J Clin Psychiatry. 2003;64(1):53-9. DOI: 10.4088/JCP.v64n0111

7) National Center for Health Statistics. NHANES 1999-2000 Data Files: Data, Docs, Codebooks, SAS Code. 2007.

8) Adams KF, Schatzkin A, Harris TB, Kipnis V, Mouw T, Ballard-Barbash et al. Overweight, obesity, and mortality in a large prospective cohort of persons 50 to 71 years old. N Engl J Med. 2006; 355:763-78. DOI: $10.1056 /$ NEJMoa055643

9) Flegal KM, Graubard BI, Williamson DF, Gail MH. Cause-specific excess deaths associated with underweight, overweight, and obesity. JAMA. 2007; 298(17):2028-37. DOI: 10.1001/jama.298.17.2028

10) Natallia G. Gabriel P, Frank S, Arseniy Y. The Relationship between BMI and Onset of Diabetes Mellitus and its Complications. South Med J. 2015;108(1): 29-36. DOI: 14423/SMJ.0000000000000214

11) Al-Nozha MM1, Al-Maatouq MA, Al-Mazrou YY, Al-Harthi SS, Arafah MR, Khalil MZ,. Diabetes mellitus in Saudi Arabia. Saudi Med J. 2004;25(11):1603-10.

12) Michael L G, Neil W, Qian Li, Veronica A, Jakob L, Mette H. The association of body mass index with the risk of type 2 diabetes: a case-control study nested in an electronic health records system in the United States. Diabetology \& Metabolic Syndrome20146:50. DOI: 10.1186/1758-5996-6-5. 
13) Khalid AA, Khalid SA, Samia AB. Prevalence of diabetes mellitus in a Saudi community. Ann Saudi Med. 2011;31(1): 19-23. DOI: 10.4103/0256-4947.75773

14) Karamatollah R, Mohammad S, Abdolreza SJ. Relation of type 2 diabetes mellitus with gender, education, and marital status in an Iranian urban population. Rep Biochem Mol Biol. 2013;1(2): 64-8.

15) Azimi-N M, Ghayour-MM, Safarian M, Esmaeili H, Parizadeh SMJ, et al. Prevalence of type 2 diabetes mellitus in Iran and its relationship with gender, urbanisation, education, marital status and occupation. Singapore Med J. 2008;49(7):571-6.

16) Bosi PL, Carvalho AM, Contrera D, Casale G, Pereira MA, Gronner MF, et al. Prevalence of diabetes and impaired glucose tolerance in the urban population of 30 to 79 years of the city of São Carlos, São Paulo. Arq Bras Endocrinol Metabol. 2009;53(6):726-32. DOI: 10.1590/S0004-27302009000600006

17) Lidfeldt J, Li TY, Hu FB, Manson JE, Kawachi I. A prospective study of childhood and adult socioeconomic status and incidence of type 2 diabetes in women. Am J Epidemiol. 2007;165(8):882-9. DOI: $10.1093 / \mathrm{aje} / \mathrm{kwk} 078$

18) Robbins JM, Vaccarino V, Zhang H, Kasl SV. Socioeconomic status and type 2 diabetes in African American and non-Hispanic white women and men: evidence from the Third National Health and Nutrition Examination Survey. Am J Public Health. 2001;91(1):76-83. DOI: 10.2105/AJPH.91.1.76

19) West KM. Epidemiology of diabetes and its vascular lesions. Elsevier Biomedical Press, 1978.

20) B. C.K.Choi et al.: Risk factors for diabetes mellitus by age and sex. Diabetologia. 2001; 44:1221-31.

21) Harris MI, BCK.Choi, et al. Diabetes in America. In: National Diabetes Data Group. 2ndedn. NIH Publication No. 95-1468. Risk factors for diabetes mellitus by age and sex 1229 National Institutes of Health, National Institute of Diabetes and Digestive and Kidney Diseases, Bethesda, 1995;1-13.

22) Dray-Spira R, Gary TL, Brancati FL. Socioeconomic position and cardiovascular disease in adults with and without diabetes: United States trends, 1997-2005. J Gen Intern Med. 2008;23(10):1634-41. DOI: 10.1007/s1 1606-008-0727-5

23) Hims worth HP, Marshall EM. The diet of diabetes prior to the onset of disease. Clin Sci Colch.1935; 2: 95-115.

24) Baird JD. Diet and the development of clinical diabetes. Acta Diabetol Lat. 1972; 9(1): 621-39.

25) Harris MI, Hadden WC, Knowler WC et al. Prevalence of diabetes and impaired glucose tolerance and plasma glucose levels in US population aged 20-74 years. Diabetes.1987;36(4):523-34.

26) Woo J, Ho SC-Donnan SP.Risk factors in non-insulin dependent diabetes mellitus in elderly Chinese in Hong Kong. Public Health.1989; 103 (1):57-66.

27) Kannel WB, Gordon T, Castelli WP. Obesity, lipids, and glucose intolerance: The Framingham Study. Am J Clin Nutr. 1999; 32:1238-45.

28) Bonham GS, Brock DB. The relationship of diabetes with race sex, and obesity. Am J Clin Nutr1987;77683.

29) Chen MK, Lowenstein FW. Epidemiology of factors related to self-reported diabetes among adults. Am J PrevMed. 1986; 2(1): 14-9. PMID: 3453155

30) Seidell JC, De Groot CPMG, van Sonsbeek J LA et al. Associations of moderate and severe over-weight with self-reported illness and medical consumption in Dutch adults. Am J Public Health1986;76: 260-64.

31) Tai TY, Chuang LM, Wu HP, Chen CJ. Association of body build with non-insulin- dependent diabetes mellitus and hypertension among Chinese adults: a 4-year follow-up study. Int J E pidemiol 1992; 21:51117.

32) Haffner SM, Stern MP, Mitchell BD, Hazuda HP, Patterson JK. Incidence of type II diabetes in Mexican Americans predicted by fasting insulin and glucose levels, obesity, and body-fat distributions. Diabetes. 1990;39(3):283-8.

33) Bouchard C, Tremblay A, Despres JP et al. The response to long-term overfeeding in identical twins. N Engl J Med.1990; 322(21):1477-82.

34) Stunkard AJ, Harris JR, Pedersen NL et al. The body-mass index of twins who have been reared apart. N Engl J Med.1990; 322(21):1483-87.

35) Danforth E. Diet and obesity. Am J Clin Nutr.1985; 41:1132-45.

36) Bray GA. Obesity -A disease of nutrient or energy balance. Nutr.1987;45: 33-43.

37) Kromhout D, Saris WHM, Horst CH. Energy intake, energy expenditure, and smoking in relation to body fatness: The Zutphen Study. Am J Clin Nutr 1988; 47:668-74. 